\title{
Non-vascularized large free fibular bone graft in post- traumatic and infectious ulnar bone defect: a case report
}

\author{
Kuldeep Nahar ${ }^{1 *}$, Nikita Nahar ${ }^{2}$ \\ ${ }^{1}$ Department of Orthopaedic Surgery, Gujarat research and medical institute, Shahibagh, Ahmedabad, Gujarat, India
${ }^{2}$ Smt. Nathiba Hargovandas Lakhmichand Municipal Medical College, Ahmedabad, Gujarat, India
}

Received: 19 July 2020

Accepted: 10 September 2020

\author{
*Correspondence: \\ Dr. Kuldeep Nahar, \\ E-mail: naharkuldeep@yahoo.com
}

Copyright: (c) the author(s), publisher and licensee Medip Academy. This is an open-access article distributed under the terms of the Creative Commons Attribution Non-Commercial License, which permits unrestricted non-commercial use, distribution, and reproduction in any medium, provided the original work is properly cited.

\begin{abstract}
This reported case is about the successful union of an adult male, having open post traumatic infected nonunion of ulna with a bone loss of ulna around $11 \mathrm{~cm}$. Difficult environment around gap nonunion makes the management more difficult for bone graft to stay there. Repeated debridement and skin courage played the key role in controlling the infection. A calculated risk of putting a non-vascular $12 \mathrm{~cm}$ autologous fibular graft fixed with plate and screws and supported with medullary nail was taken and a successful union achieved within 4.5 months. So nonvascular free can be a choice for critical bone defects nonunion in fore bones post traumatic one also.
\end{abstract}

Keywords: Open ulnar bone loss, Debridement, primary forearm nailing, Free fibular bone graft

\section{INTRODUCTION}

Traumatic bone losses in long bones can cause a significant threat to survival of limb salvation. They put serious challenges to clinicians for bone union efforts.

Bone grafts are the most important tools in spite of bone substitute, growth factors or distraction osteogenesis procedures. Bone grafts are mainly divided into non vascularized or conventional bone grafts and vascularized ones. Healing of bone grafts depends upon blood supply of recipient's bone and surrounding soft tissue environment. once the bone graft is taken out the osteocytes underneath the periosteum dies so chances of new bone growth is jeopardized if already host environment is weak.in such cases vascularized bone grafts are supposed to be the best choice. In smaller defects cancellous bone grafts are best. But if defects are fixed in between $3-6 \mathrm{~cm}$ Corticocancellous grafts are necessary to provide mechanical stability also. Defects more than $6 \mathrm{~cm}$ need other than the above methods as bone transport by monorail or ilizarov fixator. If a fibula graft harvested above $6 \mathrm{~cm}$ from the ankle, doesn't cause any instability to the joint. ${ }^{1}$

Fibular grafts allow the use of a segment of diaphyseal bone which is structurally similar to the radius and ulna and of sufficient length to reconstruct most skeletal defects of the forearm. ${ }^{2}$ Free vascularized bone grafts are better options as these makes the environment more favorable for the bone gaps to be united.

However, in this case a defect of $11 \mathrm{~cm}$ in mid shaft ulna was treated by free non vascularized fibular bone graft. In 1877 Albert first proposed the use of the fibula as a substitute for the tibia. Non-vascularized fibular graft, compared to microvascular reconstruction and Ilizarov techniques, is a simple procedure that is still valid to bridge bone defects successfully in selected cases.

\section{CASE REPORT}

27 years male right hand dominated manual worker met with an accident leading to crush injury forearm. He was 
treated primarily with debridement and intramedullary nail in both bones but after three days he developed severe infection so he took discharge and came to us. On examination there was severe pus discharge from dorsal compartment of forearm with skin necrosis and loss, loss of middle half of ulna, muscle necrosis. Open infected wound at dorsal first web space. Forearm was debrided again and dressing done for three days and taken in operation theatre for debridement.

Clinical picture after debridement post injury 7th day was as follows (Figure 1). In (Figure 2) shows an X-ray picture at the time of admission post trauma 4 days afterward.

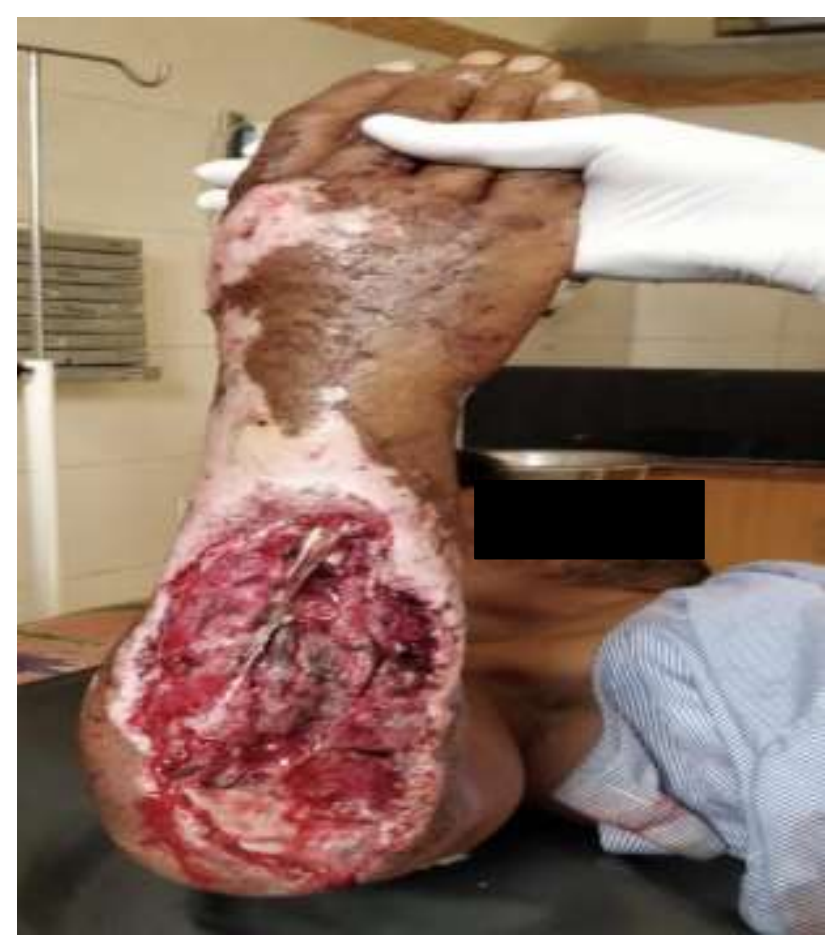

Figure 1: Crushed, infected with skin, muscle, and bone loss at ulna post trauma after a week.

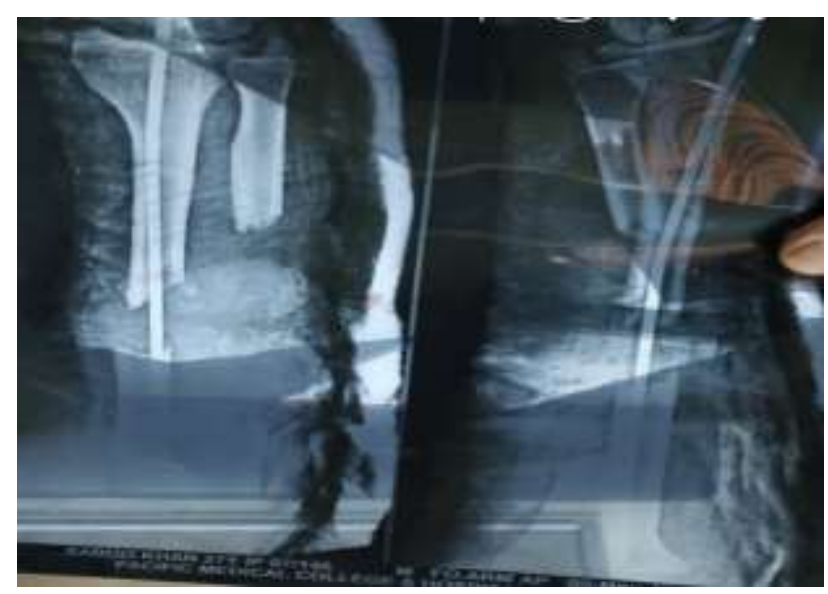

Figure 2: X-ray picture at the time of admission post trauma 4 days afterward.
Here, (Figure 3) shows the picture after debridement and renailing. (Figure 4) shows the X-ray after renailing of radius and ulna.

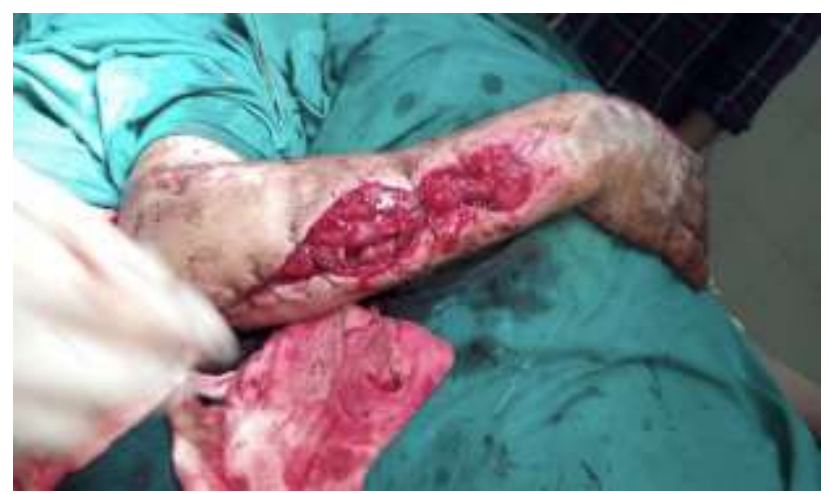

Figure 3: Picture after debridement and renailing.

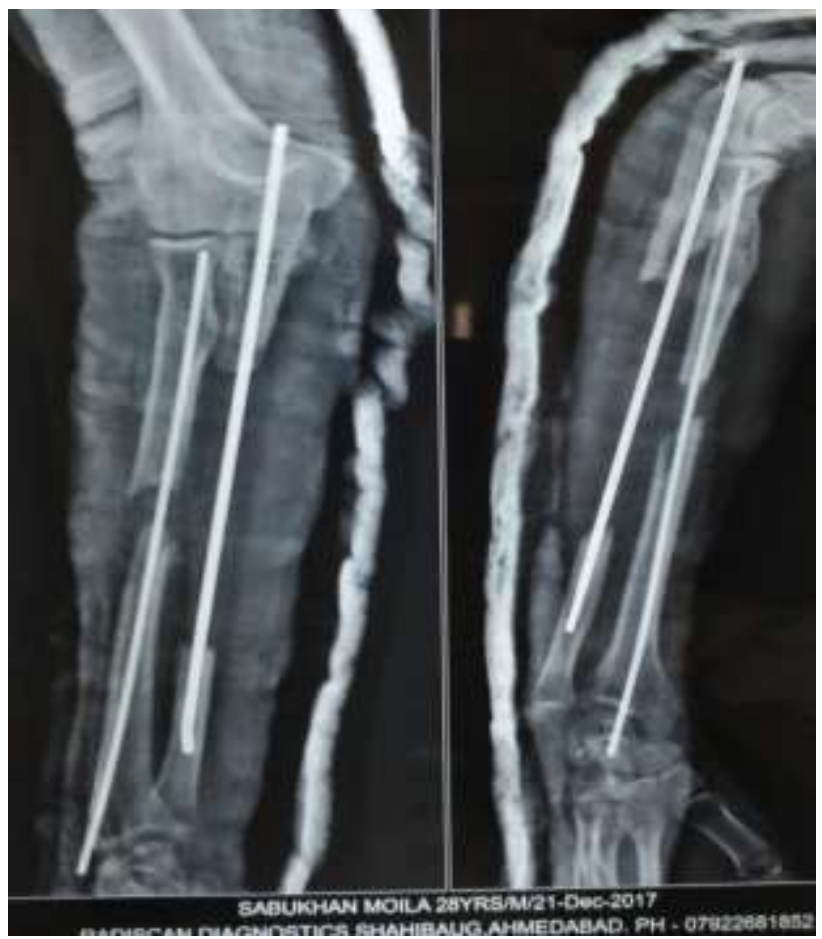

Figure 4: X-ray picture after renailing of radius and ulna.

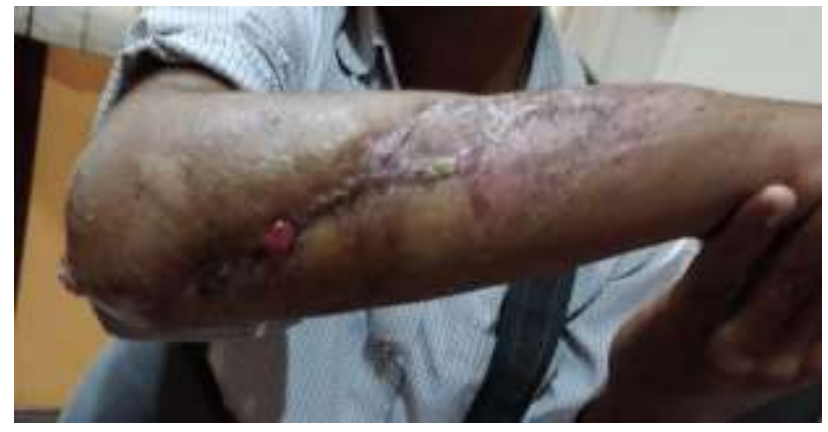

Figure 6: Clinical picture after 6 weeks post trauma. A discharging sinus at proximal ulnar fracture site. 
After few days of dressing split thickness skin graft was applied for raw area and patient was allowed to go home to be called after six weeks and picture shows like this below (Figure 5).

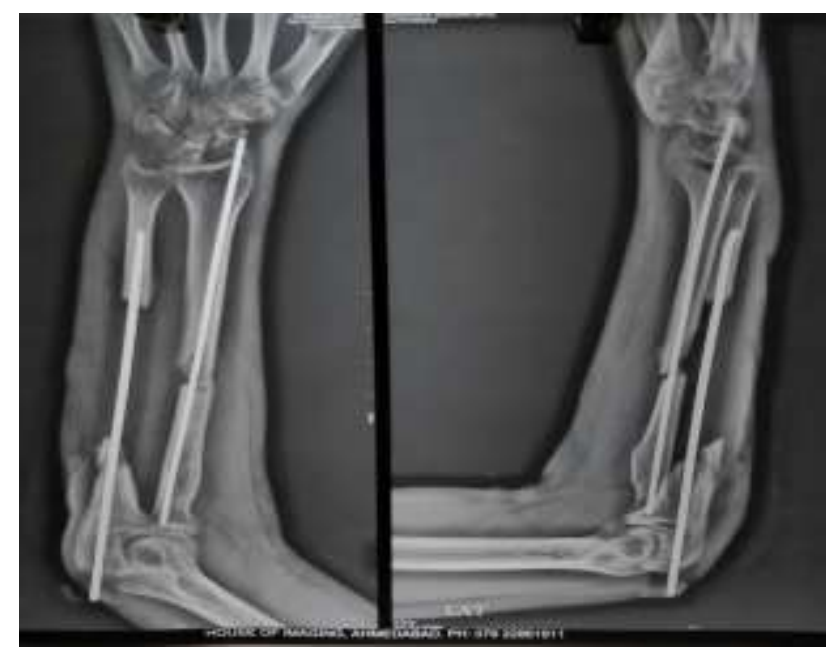

Figure 6: X-ray after renailing of radius and ulna to correct distractions.

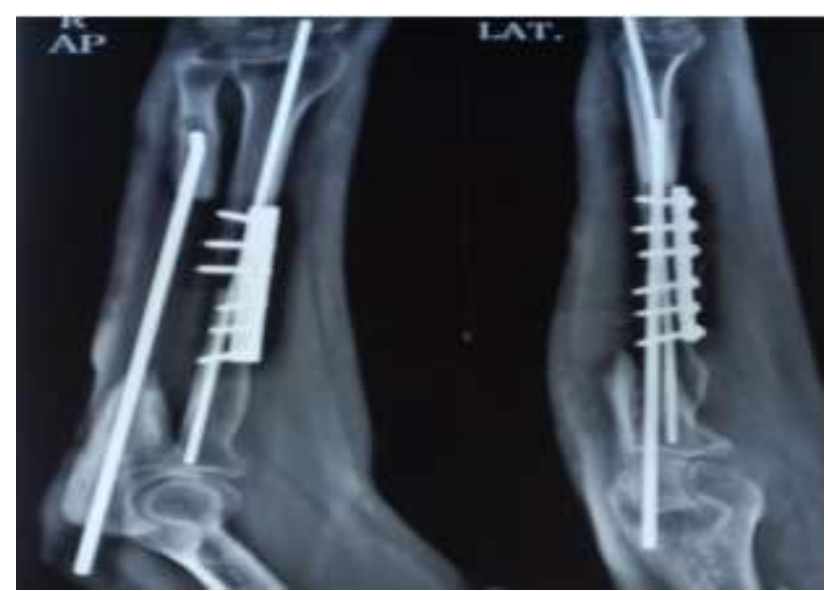

Figure 7: Plating and bone grafts for radius non-union.

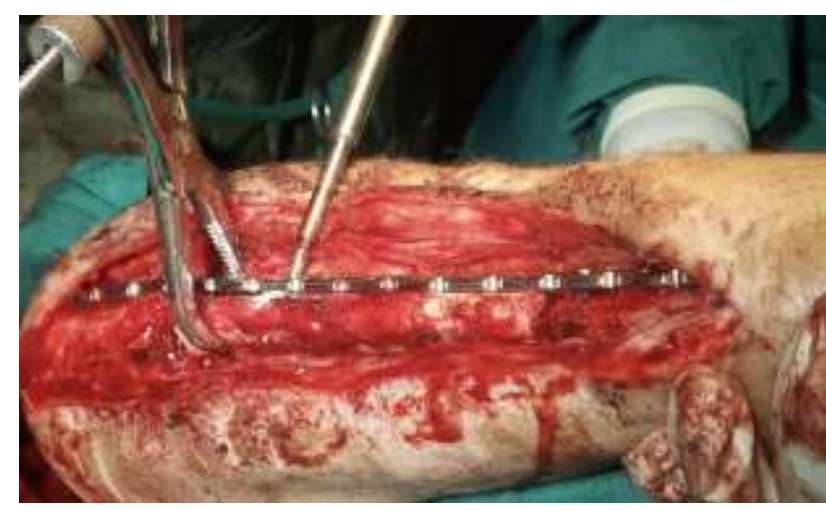

Figure 8: Intraoperative picture of fibula graft $(12 \mathrm{~cm})$ while fixation with plate to the ulnar bone loss area.
Patient was taken again for surgery and the nail was rearranged for radius collapsing the bone gap, ulnar debridement and ulnar renailing. (Figure 6) and (Figure 7) shows X-ray after renailing of radius and ulna to correct distractions.

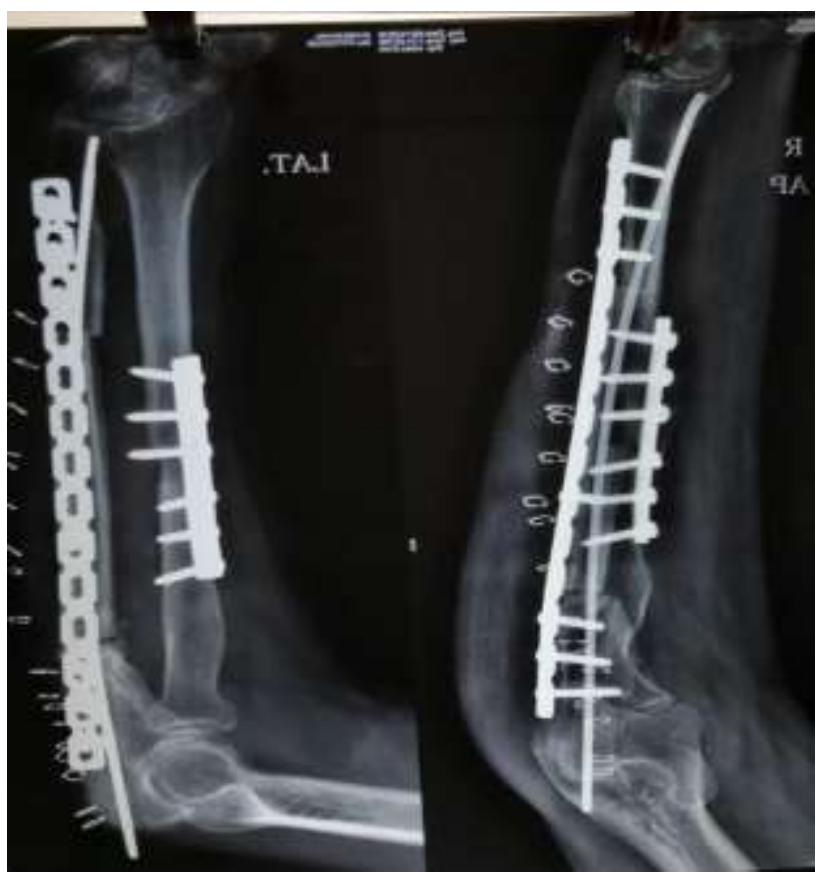

Figure 9: Immediate post op X-ray after fibular graft fixed with plate and intramedullary nail in ulna but without radial nail.

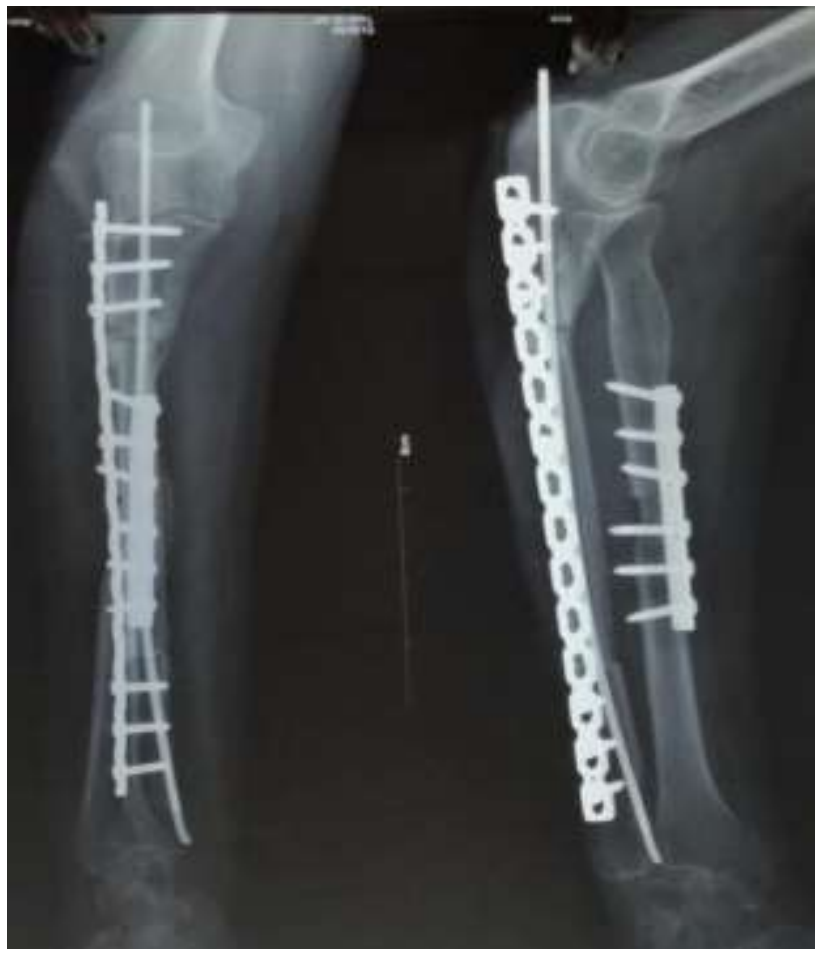

Figure 10: Complete union of ulnar bone defect in 4.5 months. 
The patient was discharged to be called after six weeks and taken for radius plating and bone graft with nail in situ. Again, the patient was discharged and recalled for ulnar defect management. After eight weeks' time ulnar defect was treated by $11 \mathrm{~cm}$ long non vascular fibular bone graft and additional reconstruction long plate with intramedullary nail through fibular graft. Radial intramedullary nail was removed during the last surgery.

Clinical intraoperative picture of fibular graft as shown below (Figure 8). Post-operative X-ray after fibular graft fixed with plate and intramedullary nail in ulna but without radial nail (Figure 9).

Here, (Figure 10) shows the complete union of ulnar bone defect in 4.5 months.

\section{DISCUSSION}

Management of critical bone losses more than $6 \mathrm{~cm}$ in long bones especially in post-traumatic but infected cases is always a challenging task. Different methods like distrac tion osteosynthesis, vascularized free fibular grafts are preferred choices for their more scientific reasons but these are either more technical demanding methods, time consuming or issue of patient compliance also.

Non vascularized fibular grafts carry more risk of refracture or get infected. In traumatic infectious cases if repeated proper debridement is done one can take calculated risk and go for non-vascularized fibular graft specially in upper limb long bones being non weight bearing bones with defined internal fixation methods.

Lemos et al carried out meta-analysis aimed to determine the bone union rate of bone defects treated with the different autologous bone graft techniques. ${ }^{2}$ The summary pooled union rate was $91 \%$ (95\% CI: 87-95\%) while union rate after additional procedures raised to $98 \%(95$ $\%$ CI: 96-99 \%). No association between union rate and bone defect size was found. Vascularized graft was associated with a lower risk of infection after surgery when compared to non-vascularized graft. Adani et al showed the results of 12 cases in which defects ranging $6-13 \mathrm{~cm}$ were treated by vascularized free fibular grafts and concluded that the vascularized fibular graft is indicated in patients with intractable non-union where conventional bone grafting has failed or large bone defects exceeding 6 $\mathrm{cm}$, in the radius or ulna. ${ }^{3}$ The mean period of radiological union was 2.5 to 8 months. ${ }^{3}$ As in our case it was also 4 . 5 months. Stevanovic et al also had the same opinion of treating the forearm defects more than $6 \mathrm{~cm}$ by free fibula grafts. ${ }^{4}$

Steinlechner et al used free non vascularized fibula and found this to be a straightforward technique with reliable results and were able to salvage the limb in all the seven patients who were reviewed. ${ }^{5}$
Tarng et al showed primary success rate of $92.6 \%$ in bone defects $2-6 \mathrm{~cm}$ treated by non-vascularized free fibula graft and concluded that with careful evaluation of soft-tissue condition surrounding bone defect, management of infected bone defects with autologous non-vascularized fibular grafts technique has a high success rate with few complications. ${ }^{6}$ Sayed et al had a success rate of $92 \%$ among 12 cases treated in a simple and effective way to bridge an average bone gap of $7 \mathrm{~cm}{ }^{7}$ Similar results were achieved by Zahrani et al who had primary union in $92 \%$ of 27 patients treated by a non-vascularized single fibular strut graft augmented with corticocancellous bone graft along its whole length. ${ }^{8}$ So literature suggests a successful use of non-vascular free fibula for bone loss management.

\section{CONCLUSION}

In critical injuries of upper limbs with infection multiple debridement and nailing are the key for the future management of definitive gaps of significant sizes. Vascularized fibula is considered superior to nonvascularized but being technically demanding and more costly to the patient. But in non-weight bearing locations non vascular bone graft can yield the same results in terms of union and function in stipulated time in management of forearm segmental bone losses.

Funding: No funding sources

Conflict of interest: None declared

Ethical approval: Not required

\section{REFERENCES}

1. Pacelli LL, Gillard J, McLoughlin SW, Buehler MJ. A biomechanical analysis of donor-site ankle instability following free fibular graft harvest. J Bone Joint Surg. 2003;85:597-603.

2. Azi LM, Aprato A, Santi I, Kfuri M, Masse A, Joeris A. Autologous bone graft in the treatment of posttraumatic bone defects: a systematic review and meta-analysis. Brtis Med Centr musculoskelet disord. 2016;17(1):465.

3. Adami R, D Luca, Innocenti M, M Ignazio, Tarallo LC, Andrea et al. Reconstruction of large posttraumatic skeletal defects of the forearm by vascularized free fibular graft. Microsurg. 2004;24(6).

4. Stevanovic M, Gutow AB, Sharpe F. The manage ment of bone defects of the forearm after trauma. Hand Clin. 1999; 15(2):299-318.

5. Steinlechner C, Wand M, Kandawire NC. Nonvascu- larised fibular transfer in the management of defects of long bones after sequestrectomy in children. J Bone Joint Surg. 2005;87-B:1259-63.

6. Tarng YW, Lin KC. Management of bone defects due to infected non-union or chronic osteomyelitis with autologous non-vascularized free fibular grafts. Injur. 2020;51(2):294-300. 
7. Sayed M, Hadidi M, Adl W. Free non-vascularized fibular graft for treatment of post-traumatic bone defects. Acta Orthop Belg. 2007;73:70-6

8. Al-zahrani S, Harding MG, Kremli M, Khan FA, Ikram A, Takroni T. Free fibular graft still has a place in the treatment of bone defects. Injur. 1993;24: $551-4$.
Cite this article as: Nahar K, Nahar N. Nonvascularized large free fibular bone graft in posttraumatic and infectious ulnar bone defect: a case report. Int J Res Orthop. 2020;6:1350-4. 